\title{
31. EL ARTÍCULO 104 DE LA CONSTITUCIÓN Y LA NUEVA REGULACIÓN DE LA INSTITUCIÓN POLICIAL: SUS DISFUNCIONALIDADES
}

\author{
FÉLIX CRESPO HELLÍN \\ Profesor Titular de Derecho Constitucional \\ Universidad de Valencia
}




\section{SUMARIO}

I. El artículo 104 Y la ambigüedad de su desarrollo.- II. Ruptura O CONTINUISMO DEL MODELO POLICIAL HISTÓRICO.— III. LOS PRINCIPALES PROBLEMAS ESTRUCTURALES DE LA LEY ORGÁNICA.- 1. Los principios básicos funcionales. 2. La denominación "Instituto armado de carácter civil». A MODO DE CONCLUSIÓN. 
Revista de Derecho Político, núm. 37, 1992, pp. 109-136

\title{
31. EL ARTÍCULO 104 DE LA CONSTITUCIÓN Y LA NUEVA REGULACIÓN DE LA INSTITUCIÓN POLICIAL: SUS DISFUNCIONALIDADES
}

\author{
POR \\ FÉLIX CRESPO HELLÍN \\ Profesor Titular de Derecho Constitucional \\ Universidad de Valencia
}

En cualquier problema con trascendencia social, ocurre que siempre encontraremos, por una parte, las intenciones o los proyectos que se quieren realizar $y$, por otra, la imagen simple y llana de las verdaderas necesidades. Esta cuestión a priori importante, se convierte en un problema fundamental cuando de una forma cierta y concluyente se transgrede -o en su caso no se cumple- el espíritu de un precepto constitucional.

En el caso del artículo 104 de la Constitución, revestido además en su desarrollo legislativo posterior por la relevancia de los aspectos formales de una Ley Orgánica, denotamos un incumplimiento patente de este espíritu constitucional. Una vez aprobada la Ley Orgánica, y dotado el Cuerpo Policial de unas variantes sustancialmente determinantes, resulta ser que éstas quedan desajustadas y faltas de acoplamiento con el precepto mencionado.

Ha sido patente la disfuncionalidad entre el texto de la Ley Orgánica 2/1986, de 13 de marzo, de Fuerzas y Cuerpos de Seguridad, y la realidad social. No se ha solucionado la mayoría de los problemas importantes, y casi podríamos decir que esa Ley histórica con que se iba a regular la institución policial debería tener ese calificativo por la oportunidad que se ha perdido para realizar un verdadero cambio en la Policía. 


\section{EL ARTÍCULO 104 Y LA AMBIGÜEDAD DE SU DESARROLLO}

Queda claro desde un principio que la Ley Orgánica 2/1986 se refiere exclusivamente a la Policía en sentido orgánico, y no a la función de policía en sentido material. Eso significa que en esta norma se recogen las directrices sobre la estructura, régimen estatutario, organización, principios básicos de actuación, etc., de los Cuerpos dePolicía, quedando fuera del mismo aquellas otras que regulan los diferentes ámbitos en que se concreta la función de los órganos policiales, tales como, la Ley de los estados de alarma, excepción y sitio, la Ley de medidas contra la actuación de bandas armadas y actividades terroristas o rebeldes, la Ley de derechos y libertades de los extranjeros en España, la Ley de protección civil, etc. Todas ellas aparecen, sin embargo, concordadas con los correspondientes preceptos de esta legislación.

Volviendo a la idea inicial de que es concebida la institución policial como cuerpo separado del ámbito militar, el modelo policial implantado en nuestro país tras la entrada en vigor de la Constitución de 1978 se asienta sobre tres pilares fundamentales:

- En primer lugar, para definir la misión de los Cuerpos de Policía se ha abandonado el concepto de orden público que queda ahora sustituido por el de seguridad ciudadana.

- En segundo lugar, nuestra norma suprema ha deslindado claramente las competencias de las Fuerzas Armadas y las de las Fuerzas y Cuerpos de Seguridad (arts. 8 y 104 de la Constitución), atribuyendo con carácter exclusivo a los segundos el mantenimiento de la seguridad pública ${ }^{1}$.

- En tercer lugar, la nueva organización territorial del Estado ha determinado la existencia de Cuerpos de Policía estatales, autonómicos y locales.

Comprobamos así - sin ánimo de ser reiterativos, sino con la intención de resaltar la base de este nuevo cuerpo policial- que la Constitución

1 Estas ideas ya se venían apuntando y reiterando en diferentes obras, destacando entre otras: G. PECES-BARBA y otros: La izquierda y la Constitución. Barcelona, 1978, y en M. Ballbé y M. Giró: Las Fuerzas de Orden Público. Barcelona, Colección "Los Marginados", Dopesa, 1978. 
ha desconectado las misiones de las Fuerzas y Cuerpos de Seguridad del concepto de orden público, noción que aparece muy ambigua y demasiado amplia, pues engloba muchos aspectos que nada tienen que ver con la actuación policial y que, como es sabido, fue durante mucho tiempo una cláusula de apoderamiento a la Administración que ha servido para amparar prácticas restrictivas o ablativas de los derechos y libertades fundamentales. A las Fuerzas y Cuerpos de Seguridad corresponde ahora proteger el libre ejercicio de los derechos del ciudadano y garantizar la seguridad pública, concepto éste más estricto que el del orden público, que se refiere - según la definición que del mismo ha formulado el Tribunal Constitucional- a la uprotección de las personas y a la preservación y el mantenimiento de la tranquilidad y del orden ciudadano" ${ }^{2}$.

Definido en estos términos el concepto de seguridad pública y atribuido su mantenimiento a las Fuerzas y Cuerpos de Seguridad, quedan ya perfectamente separadas las competencias de éstos y las que corresponden a las Fuerzas Armadas -o sea, seguridad interior o seguridad pública o ciudadana para unos, y seguridad exterior o defensa para otros-. La actuación delas Fuerzas Armadas queda, pues, excluida del ámbito de la seguridad pública.

De acuerdo con ello, la Ley Orgánica 2/1986 viene a "desmilitarizar» las Fuerzas y Cuerpos de Seguridad, equiparándolos al resto de los sectores que integran la administración civil, sin perjuicio de las peculiaridades derivadas de la misión que estos funcionarios realizan. La Ley atribuye, por eso, importantes competencias a la Dirección de la Seguridad del Estado, de la que dependen las Direcciones Generales de la Guardia Civil y de la Policía. Con ello se pretende asumir «la idea de que sobre las organizaciones y cuerpos policiales existe una cúpula civil, una cúpula que emana del poder político, que a su vez emana del poder soberano del pueblo, $y$ que esta cúpula es la que dirige toda la política policial, toda la política de seguridad ${ }^{3}$.

A partir de la entrada en vigor de la Ley Orgánica quedan integradas por el Cuerpo Nacional de Policia y la Guardia Civil (Fuerzas y Cuerpos de Seguridad del Estado, dependientes del Gobierno de la Nación), por los Cuerpos de las Comunidades Autónomas y por las Policías Locales.

2 Vid. STC núm. 33/1982, de 8 de junio, fundamento jurídico núm. 3, y STC núm. 123/1984, de 18 de diciembre, fundamento jurídico núm. 4, en Boletín de Jurisprudencia Constitucional.

3 Diario de Sesiones del Congreso de los Diputados, núm. 259, de 10 de diciembre de 1985, pág. 11730 . 
El Cuerpo Nacional de Policía, de naturaleza civil, refunde los dos Cuerpos anteriormente citados. Su definición como "Instituto armado" fue duramente criticada por la mayoría de grupos parlamentarios, que la tacharon de vacía, nominalista e innecesaria. A pesar de las numerosas enmiendas a favor de su supresión - como ahora comprobaremos-, el término se mantuvo; probablemente con el fin de sujetar a los funcionarios de este Cuerpo a las restricciones que respecto del derecho de sindicación prevé el artículo 28.1 de nuestra Ley suprema para «las Fuerzas o Institutos armados».

La Guardia Civil se conceptúa, por el contrario, como "Instituto Armado de naturaleza militar", lo que constituye para muchos un punto que contradice la "vocación desmilitarizadora" que late en el articulado de la Ley. En efecto, mantener un cuerpo de seguridad con disciplina militar y estructura militarizada $y$, además, sujeto a una doble dependencia (Ministerio del Interior y Ministerio de Defensa) es una nota disonante que se compadece mal con la clara distinción entre las funciones de las Fuerzas Armadas y las Fuerzas de Seguridad que la propia Constitución ha efectuado.

Sin perjuicio de las peculiaridades que la naturaleza civil o militar ha de entrañar para cada uno de los cuerpos citados -incluidos Policías autónomas y locales-, la ley contiene una serie de disposiciones comunes a todo ello. De un lado, los principios básicos de actuación (art. 5. ), los cuales se concretan fundamentalmente en el respecto a la Constitución y al resto del ordenamiento jurídico, el comportamiento correcto y esmerado con los ciudadanos, el trato a los detenidos, por cuya vida e integridad física habrán de velar, respetando siempre su honor e integridad, $y$, por último, la necesidad de ajustar su actuación a los principios de congruencia, oportunidad y proporcionalidad en la utilización de los medios a su alcance. Por ello dispone que solamente podrán usar las armas en defensa de la vida e integridad física, propias o de terceras personas, o en aquellas circunstancias que puedan suponer un grave riesgo para la seguridad ciudadana.

De otro, la Ley establece un régimen disciplinario común, así como también otro de carácter estatutario en la mayor parte de sus disposiciones, para todos los miembros de las Fuerzas Armadas y Cuerpos de Seguridad. Destacan entre ellos el relativo a los derechos de huelga y sindicación y el referente al régimen disciplinario.

En cuanto al primero de los aspectos apuntados, se prohibe terminantemente a los miembros de las Fuerzas y Cuerpos de Seguridad el ejercicio del derecho de huelga o de acciones sustitutivas del mismo, a la vez que se califica de sanción muy grave la participación en ellas. La supresión 
del ejercicio de un derecho constitucional tan importante como éste se justificó con el argumento de que la interrupción del servicio de Policía podría provocar un perjuicio irreparable en el funcionamiento de la sociedad y en la convivencia ciudadana 4 . Para paliar el sacrificio de este derecho, se crea el Consejo de Policía, una de cuyas funciones es la mediación y conciliación en caso de conflictos colectivos en el seno del Cuerpo Nacional de Policía; la presidencia del ministro del Interior enturbia, sin embargo, el carácter paritario que, según la Ley, tiene este órgano.

En materias de derechos sindicales, la Ley Orgánica separa a la Guardia Civil —con una prohibición tajante de poder pertenecer a sindicatos- del resto de Cuerpos policiales, los cuales sí podrán acceder al derecho de sindicación, si bien con algunas limitaciones, derivadas de las funciones que este Cuerpo desarrolla y del grado de jerarquización y disciplina interna de los mismos. No obstante, estos límites - ha dicho el Tribunal Constitucional- «en cuanto restringen un derecho fundamental han de ser interpretados a su vez restrictivamente" ${ }^{5}$.

En cuanto al régimen disciplinario se contienen regulaciones distintas según sea la naturaleza —civil o militar- del Cuerpo. Así, el artículo 15 dispone que, a estos efectos, la Guardia Civil se regirá por su «normativa específica». Pues bien, mientras no se apruebe el reglamento disciplinario propio de este Cuerpo, parece lógico que se le aplique el régimen disciplinario de las Fuerzas Armadas, regulado por la Ley Orgánica 12/1985, de 27 de noviembre.

Esta es, a nuestro parecer, la solución más congruente que puede ofrecerse ante la indeterminación creada por el precepto citado: primero, porque la Ley ha optado por mantener la naturaleza militar de la Guardia Civil, con lo que sus miembros están sujetos a una jeraquía y disciplina castrense, $y$, segundo, porque a lo largo del articulado de la Ley 12/1985 se encuentran algunas previsiones sobre el régimen disciplinario del Cuerpo que nos ocupa.

La Sección cuarta del Capítulo IV del Título II de la Ley regula el régimen disciplinario de los Institutos Armados de naturaleza civil, aplicable, por tanto, al Cuerpo Nacional de Policía, a las Policías de las Comunidades Autónomas, salvo aquellas que se rijan por su reglamento especifico, y a las Policías Locales. Para cubrir las lagunas que quedan en la ley

4 Diario de Sesiones del Congreso de los Diputados, núm. 232, de 1 de octubre de 1985, pág. 10541.

5 STC $81 / 1983$, de 10 de octubre, fundamentos jurídicos núms. 2 y 3 , en $B o-$ letín de Jurisprudencia Constitucional. 
(determinación de las faltas graves y leves y sus sanciones y del procedimiento sancionador), la disposición transitoria 4. 2 declara vigente el Real Decreto 1346/1984, de11 de julio, sobre el régimen disciplinario del Cuerpo Superior de Policía.

Para terminar con este tema, hay que recordar que la incoación y tramitación de expedientes disciplinarios no excluye la posibilidad de iniciar - por los mismos hechos- un proceso penal contra los miembros de las Fuerzas y Cuerpos de la Seguridad. De los delitos que se cometan contra éstos, así como de los cometidos por ellos en el ejercicio de sus funciones, conocerá la jurisdicción ordinaria, siendo competente para instruir, procesar, en su caso, y fallar la Audiencia Provincial. La Ley mantiene así un fuero judicial para estos funcionarios que se separa del que es un principio general y una garantía del proceso penal; la diferenciación entre el órgano que instruye y el que juzga. En este sentido, el Tribunal Constitucional ha admitido a trámite una cuestión de inconstitucionalidad sobre el artículo $8 .^{\circ} 1.2$ de la Ley ${ }^{6}$.

La nueva estructura territorial del Estado iba a exigir, sin duda, una importante reforma en la organización y articulación de los Cuerpos de Policía. De acuerdo con ello, y en desarrollo de los mandatos constitucionales contenidos en los artículos 148.1.22 y 149.1.29, la Ley Orgánica ha establecido el régimen de las Policías Autonómicas y Locales.

En cuanto a los Cuerpos de Policía de las Comunidades Autónomas, el modelo regulado en esta Ley queda definido desde su artículo $1 .^{\circ}$ : "La seguridad pública - reza el citado precepto-es competencia exclusiva del Estado. Su mantenimiento corresponde al Gobierno de la Nación". Las Comunidades Autónomas y las corporaciones Locales, se dice en los párrafos siguientes, "participan" en el mantenimiento de la misma. Esta fórmula suscitó durísimas críticas por parte de algunos grupos parlamentarios, sobre todo los nacionalistas, que defendían la existencia de una titularidad autonómica propia en la materia, frente a la mera participación en el ejercicio de una competencia estatal que la Ley reconoce.

Pues bien, el enunciado del artículo $10^{\circ}$, así como el modelo de Policías Autonómicas implantado por la Ley, son, a nuestro entender, respetuosos con la delimitación competencial que la Constitución hace, respecto de esta materia, en los artículos $104.1,148.1 .22$ y 149.1.29. A la lectura de estos preceptos, cuyo tenor literal ya hemos citado en páginas anteriores, hay que añadir la interpretación que de los mismos ha hecho el Tribunal Constitucional. En su sentencia 117/1984, de 5 de diciembre, el alto Tri-

$6 \quad$ BOE núm. 173, de 21 de julio de 1986. 
bunal ha afirmado que "corresponde al Estado la competencia exclusiva en materia de seguridad pública; ahora bien, continúa diciendo, «dado que el artículo 149.1.29 (...) hace la salvedad de que ello es así sin perjuicio de la posibilidad de creación de policías por las Comunidades Autónomas en la forma que se establezca en los respectivos Estatutos en el marco de lo que disponga una ley orgánica, es preciso examinar lo que sobre este punto dispone el Estatuto de Cataluña (...). El artículo 13 del mismo habilita a la Generalidad para crear una Policía autónoma (...). Este precepto, sin embargo, como el propio artículo 149.1.29 de la Constitución en que se basa, se refiere al aspecto orgánico, es decir, al del servicio disponible para garantizar la seguridad pública (la Policia), no al respecto material, la seguridad pública, por lo que la existencia de tal Policía autónoma no modifica la titularidad estatal de la competencia controvertida ${ }^{7}$. En sentencias posteriores, el Alto Tribunal ha vuelto a insistir en esta doble idea de que se trata de una competencia inalienable y exclusiva del Estado ${ }^{8}$, y que el concepto de "seguridad pública" del artículo 149.1 .29 es un concepto estricto, "en el que hay que situar el modo predominante las organizaciones y los medios instrumentales, en especial de los Cuerpos de Seguridad a que se refiere el artículo 104.1 de la Constitución ${ }^{9}$.

Por último, no puede olvidarse que, en le caso del artículo 149.1.29, nuestra Constitución ha hecho una remisión concreta y específica a una Ley del Estado para precisar el alcance de las competencias que las Comunidades Autónomas pueden asumir en el ámbito de la seguridad pública. Esa ley es, precisamente, la Ley Orgánica 2/1986, que, junto con nuestra norma suprema y los Estatutos de Autonomía, constituyen el bloque de la constitucionalidad en esta materia.

La Ley ha establecido cuatro regímenes diferentes para las Policías Autónomas. En primer lugar, para el País Vasco, Cataluña y Navarra dispone que a sus respectivos Cuerpos policiales sólo se les aplicarán los preceptos de la Ley que contienen los principios básicos de actuación y las disposiciones estatutarias comunes (art. $5 .^{\circ}, 6 .^{\circ}$, y $7 .^{\circ}$ y $8 .^{\circ}$ ). Dentro de este primer grupo se hace todavía otra distinción, pues se prevé que, además de los preceptos citados, serán de aplicación directa los artículos 38,43 y 46 en Cataluña, y los artículos 38, 39, 43, 46 y 46 en Navarra. En segundo lugar, y para el resto de las Comunidades Autónomas, el artículo 37 ha establecido los tres siguientes niveles:

7 STC núm. 117/1984, de 5 de diciembre, fundamentos jurídicos núms. 3, 4 y 5 , en Boletín de Jurisprudencia Constitucional. cit.

8 STC núm. 123/1984, de 18 de diciembre, fundamento jurídico núm. 4, loc.

9 STC 59/1985, de 6 de mayo, fundamento jurídico núm. 2, loc. cit. 
1. Comunidades Autónomas en cuyos Estatutos esté prevista la posibilidad de crear Cuerpos de Policía propios y los creen. Para éstos la Ley fija las competencias propias, competencias en colaboración con las Fuerzas y Cuerpos de Seguridad del Estado y competencias de prestación simultánea e indiferenciada con las mismas.

2. Comunidades Autónomas que, habiendo admitido estatutariamente la competencia para crear Cuerpos de Policía, no hicieran uso de la misma. Para éstas la Ley dispone que podrán solicitar del Gobierno de la Nación la adscripción de unidades del Cuerpo Nacional de Policía que dependerán, funcionalmente, de las autoridades de la Comunidad Autónoma y, orgánicamente, del Ministerio del Interior.

3. Comunidades Autónomas cuyos Estatutos no prevén la creación de Cuerpos de Policía. Éstas podrán ejercer las funciones de vigilancia y protección a que se refiere el artículo 148.1.22 de la Constitución mediante la firma de acuerdos de cooperación específica con el Estado.

Quedaría, por último, señalar lo referente a las Policías Locales y a su rasgo más importante de creación, como es la Junta Local de Seguridad, cuya principal misión será la de coordinarse Policía Municipal-Fuerzas y Cuerpos de Seguridad que actúen en su territorio. Destaca que la presidencia de las mismas estará ocupada por los Alcaldes de modo exclusivo, aunque puede llegar a ser compartida con el Gobernador Civil en el caso de que éste acudiese a sus reuniones.

Destaca también la creación de las Unidades de Policía Judicial, las cuales son concebidas por la ley como unidades de carácter nacional, es decir, integradas exclusivamente por miembros de la Policía estatal, lo que significa que las Policías Autonómicas y Locales tienen en este ámbito un carácter meramente colaborador de aquéllas.

Esta es una nueva cuestión de polémica, ya que esta opción centralizada parece contradecir lo previsto al respecto por la Ley Orgánica del Poder Judicial cuyo artículo $\mathbf{4 4 3}$ atribuye la función de la Policía Judicial a "todos los miembros de las Fuerzás y Cuerpos de Seguridad, tanto si dependen del Gobierno central como de las Comunidades Autónomas o de los Entes locales». Sin embargo, no cumple este dictado la nueva Ley Orgánica de Policía, ya que deja a las Policías Autonómicas y Locales relegadas a ejercer simple papel de colaboradores con los Cuerpos de carácter nacional.

Abundando un poco más, podríamos encontrar una nueva contra- 
dicción en lo referente a la Policia Judicial, cuando hablando de ellas, el anterior precepto cita que, junto a las misiones que le son propias, desempeñarán "las demás que se le encomienden (...) de entre las correspondientes a las Fuerzas y Cuerpos de Seguridad del Estadon. Sin embargo, por su parte, la Ley Orgánica del Poder Judicial dispone que "en ningún caso podrán encomendarse a los miembros de dichas Unidades la práctica de actuaciones que no sean las propias de la Policía Judicial o las derivadas de las mismas" (art. 445.2).

\section{RUPTURA O CONTINUISMO DEL MODELO POLICIAL HISTÓRICO}

A pesar de todo, hay que volver a recordar que el lastre histórico de la fuerza pública en nuestro país (carácter decimonónico de la Guardia Civil, con su esencia de cuerpo separado; el despliegue, estructura y organización de la Policia Nacional, propias de paises subdesarrollados; el arrinconamiento de las autoridades gubernativas no centrales y de los Cuerpos policiales no estatales, etc) ha venido a determinar, una vez en vigor la Constitución, su inadecuación a las exigencias democráticas, así como la necesidad de construir una verdadera Administración de Seguridad Pública que garantice el principio de separación de fuerzas y la subordinación de éstas a la función, encarnada en la competencia de las autoridades gubernativas civiles ${ }^{10}$. Parece lógico afirmar - frente al pasado- que el mantenimiento del orden interior corresponde a las autoridades gubernativas, que reciben a tal fin una serie de competencias servidas a través de las misiones que se señalan a los Cuerpos de Seguridad. Así pues, con la aparición en su día del Proyecto de Ley Orgánica de Fuerzas y Cuerpos de Seguridad ${ }^{11}$, parecía que se iba a recoger, aunque tímidamente, el citado

10 Destaca que autores como Morales Villanueva, en su libro Las Fuerzas de Orden Público. Madrid, San Martín, 1980, a pesar de su condición de capitán de la Guardia Civil, escriba con relación a la Policía Nacional: "No comprendemos las razones por las que un cuerpo civil debe tener estructura y organización militar, ni tampoco estar sujeto al código castrense en cuanto a su disciplina interna. Ello equivale a una militarización permanente (...) como cuerpo totalmente civil, de cara a la población y a todos sus servicios, hagámoslo igualmente para su régimen interno. Lo contrario es mantener a sus funcionarios en un estado de permanente injusticia y desigualdad".

11 Vid BOCG, Congreso de los Diputados, II Legislatura, Serie A, núm. 163-I (18 de septiembre de 1985). El informe de la Ponencia, en igual Boletín de fecha de 25 de noviembre de 1985, y el Dictamen de la Comisión de Justicia e Interior, junto con las enmiendas y votos particulares, en el de 3 de diciembre de 1985. 
principio ${ }^{12}$. Posteriormente se podría comprobar cómo terminaba atribuyendo a los Cuerpos policiales lo que son competencias propias de las autoridades gubernativas ${ }^{13}$, El Proyecto mantenía las perspectivas de que, asignando funciones a los Cuerpos de Seguridad y colocando éstos bajo el mando del Ministerio del Interior, el Director de la Seguridad del Estado y los Gobernadores Civiles ${ }^{14}$, o de la Comunidad Autónoma, se conseguían los mismos resultados. Frente a esta idea, el artículo $3 .^{\circ}$ del Proyecto de Ley de Seguridad Ciudadana ${ }^{15}$ establecía una auténtica Administración de seguridad ciudadana, con indicación de las autoridades gubernativas y sus competencias, objetivando competencias materiales y territoriales, pasando a un segundo plano - el que le es propio- el tema del Cuerpo de Seguriad que se ocuparía de desarrollarlas. El expediente de designar mandos y no competencias es tanto una vía de desadministrativización como la traducción de que existe un poder de Policía autónomo y distinto, al margen del Derecho Administrativo.

El diseño de los órganos de coordinación y cooperación ${ }^{16}$, o la Junta de Seguridad, supone el intento en el proyecto inicial de formular esa Adminstración de seguridad sobre la base de la intervención de distintas Administraciones.

Al margen de esto, la "fuerza policial» era aludida en el proyecto con la expresión "Instituto Armado" (arts. 8., 39 y 51 del Proyecto) -término que perduró en la redacción definitiva, como ya hemos visto-, aplicable a los tres sectores del Cuerpo policial ${ }^{17}$. En apoyo de aquella expresión - que traduce toda una concepción sobre la "fuerza" se citan los artículos 28 y 29 de la Constitución. No parece lícito utilizar estos artículos

12 Artículo $1 .^{\circ}$ b) del Proyecto y artículo 36.1.d) del Dictamen de la Comisión de Justicia e Interior.

13 Asi, el artículo 10.2 del Proyecto diferenciaba entre competencias upor razón de la materia" que pertenecian a la Guardia Civil y al Cuerpo Nacional de Policía, formulando ámbitos competenciales que en realidad pertenecen a las autoridad gubernativas.

14 Artículo 9. ${ }^{\circ}$ del Proyecto.

.15 Vid BOCG, Congreso de los Diputados, I Legislatura, Serie A, núm. 73-I. El proyecto pretendia normativizar el ejercicio de las potestades administrativas de carácter gubernativo y preveía la derogación expresa de la Ley de Orden Público de 30 de julio de 1959.

${ }_{16}$ Artículo 46 del Proyecto.

17 Artículo 50 del Dictamen de la Comisión. Recuérdese sobre este punto que la Ley 7/1985, de 2 de abril, reguladora de las Bases de Régimen Local, atribuye a los municipios competencias (uen los términos de la legislación del Estado y de las Comunidades Autónomas», art. 25) en materia de seguridad pública («en lugares públicos") e igualmente en materia de protección civil (art. 25). Tales competencias sólo puede determinarlas la Ley (art. 25.3). 
para conceptuar toda la fuerza policial, porque en ellos se aluda únicamente a quellos "Institutos sometidos a disciplina militar", de forma que es contradictorio hablar de Institutos armados de carácter civil. Esta expresión es equivalente a la de ufuncionarios que usen armas en el desempeño de sus misiones", pero al utilizarla se trata de restringir el reconocimiento de libertades sindicales, apoyándose en el artículo 28 de la Constitución cuando, rectamente interpretado, los miembros de los Cuerpos policiales "no sometidos a disciplina militar» gozan de la misma libertad sindical peculiarizada, pero no limitada, que el resto de los funcionarios públicos ${ }^{18}$. En esta línea, la jurisprudencia afirmó no ser lícito prohibir el ejercicio del derecho de manifestación a los miembros del Cuerpo General de Policía, aduciendo únicamente el carácter de policías de sus miembros ${ }^{19}$. Y la Sentencia del Tribunal Constitucional 81/1983, de 10 de octubre, parece rechazar la expresión "Instituto armado de carácter civil», reconociendo, por el contrario, la de "funcionarios que usen armas", siéndoles aplicables las restricciones de derechos que exija el carácter prevalente de los bienes constitucionales que se les encomiendan, pero no fundamentadas en ser "Institutos armados de carácter civil» que hay que entender, repetimos, no aludidos en el artículo 28 de la Constitución ${ }^{20}$.

18 Sobre la libertad sindical de los miembros de la Policía, es esencial el planteamiento genérico de L. ORTEGA: Los derechos sindicales..., cit. Vid. también, M. Fernando Pablo: "Ejército, Policía y libertad sindical", en Revista de Política Social, núm. 144, págs. 101-152.

19 La Administración alegaba que los funcionarios de policía no podían reunirse por estar en servicio permanente. La sentencia dice que esta normativa queda derogada y ucede siempre ante un precepto constitucional y no puede ser interpretado de forma tan literal y desorbitada que anule o convierta en ineficaz la factibilidad del ejercicio de un derecho fundamental que al no serles negado por la Constitución ostenta en principio como los demás ciudadanos".

Respecto a la sindicación existe una sentencia del Tribunal Europeo de Derechos Humanos de 27 de octubre de 1975 reconociéndolo a los policías (Cfr. en M. BALlBÉ: "La Policía y la Constitución", en Policía y sociedad democrática. Dirección de la Seguridad del Estado, Madrid, 1983, pág. 95). La sentencia del Tribunal Supremo de 9 de julio de 1982 y demás son citadas por M. BALLBÉ: "La Policía y la Constitución", cit.

20 La STC 81/1983, de 10 de octubre, se ocupa del recurso de amparo interpuesto por el secretario de Propaganda del Sindicato Provincial de la Unión Sindical de Policía contra las resoluciones de la Dirección de Seguridad del Estado, confirmadas en vía contenciosa, por las que se le sancionaba por el contenido de una nota de prensa. El Tribunal Constitucional deniega el amparo, argumentando que los bienes jurídicos protegidos a través de los principios de subordinación y jerarquía hacen que éstos deban prevalecer sobre las manifestaciones y actividades sindicales que los contradigan frontalmente. Pero no fundamenta su fallo, directamente, en las "limitaciones de la libertad sindical» de que habla el artículo 28 de la Constitución. 
Con la expresión comentada se alude en realidad, por una parte, a la estructura y organización jerarquizada y disciplinada de estos cuerpos (art. 5. ${ }^{\circ}$ del Proyecto), y, por otra, al elemento institucional de la Policía: si ésta es tanto una organización como una profesión, ambas se funden en aquel concepto. Desde esta perspectiva, el principio de separación de fuerzas se traduce en separación de instituciones FF.AA./Institutos Armados. Si ambos se asientan en el principio de jerarquía debe señalarse que la ujerarquía militar" es una jerarquía de grado, personalizada, antes que una jerarquía de "oficios" u órganos, como es el caso de la Administración civil. Por eso, la institución militar tiene como principio obediencia a todo superior y la asunción por el superior de la responsabilidad ${ }^{21}$. Este esquema no es apropiado (y recuérdese que el propio Tribunal Constitucional, en Sentencia de 15 de junio de 1981, ha reconocido que la subordinación jerárquica y la disciplina militar constituyen valores principales del ordenamiento militar) para las misiones de orden interior, donde la Policía debe actuar con un grado de discrecionalidad considerable, asumiendo la responsabilidad. De ahí que en el artículo $4 .^{\circ}$ del Proyecto ya se estableciera la asunción de la responsabilidad por el agente de forma personal y directa, por su actividad, vulnerando los principios legales de actuación. Es contradictorio, pues, con este principio la sumisión de un Cuerpo policial -la Guardia Civil- a la jerarquía militar, en cuanto ésta 22 conlleva la asunción de responsabilidad por el superior. Aun afirmando que, en el cumplimiento de las misiones que la Ley le encomienda, los miembros de la Guardia Civil están sometidos a la responsabilidad personal, se pone de manifiesto la inadecuación del modelo propuesto y la difícil posición de aquéllos ${ }^{23}$. No se trata tanto de la doble dependencia de la Guardia Civil (arts. 12 y 13), sino de establecer una línea divisoria, apuntada ya en el Proyecto ${ }^{24}$, a través de los procedimientos de puesta en acción, entre misiones policiales ordinarias y aquellas otras en que la Guardia Civil actúa como fuerza armada.

21 Vid. V. BACHELET: Disciplina militare e ordinamento giuridico statale. Giuffrè, Milán, 1962, p. 232, y M. VolPI: "Costituzione e Polizia", en Politica del dirito, núm. 1, 1983, págs. 31-116.

22 Artículos 12,32 y 79 de las Reales Ordenanzas para las Fuerzas Armadas.

23 El problema no se soluciona con la no obligatoriedad de los órdenes lega les. Quizá por eso, en el Derecho alemán se distinguió, a efectos penales, entre el mandato y su obligatoriedad. Vid J. Rodríguez DeVESA: "La nueva ley penal mili. tar alemana", en Boletín del Seminario de Derecho Político. Universidad de Salamanca (mayo-octubre 1957), págs. 72 y ss. rior.

24 Vid. artículos $6 .^{\circ} 3$ y $8 .^{\circ}$ del dictamen de la Comisión de Justicia e Inte- 


\section{LOS PRINCIPALES PROBLEMAS ESTRUCTURALES DE LA LEY ORGÁNICA}

En una sociedad democrática, el poder recoge sus facultades del consenso legimitador que surge del apoyo de los votos populares y se refuerza con el grado de coincidencia que para determinadas actuaciones $y$ fines puedan otorgarle otras opciones políticas y sociales normalmente situadas en las zonas de la contradicción y el disenso. Ahora bien, por muy numeroso y hasta abrumador que sea el grado de consenso alcanzado para llevar a cabo una decisión legislativa - como así ha sido en la configuración de esta Ley Orgánica-, nunca su plasmación en texto legal puede suponer una restricción de las libertades ni una degradación de la legalidad constitucional.

Hemos visto cómo el artículo 104.1 de la Constitución española encomienda a las Fuerzas y Cuerpos de Seguridad la protección del libre ejercicio de los derechos y libertades de los ciudadanos y garantizar su seguridad. La actividad cotidiana de los policías incide sobre los derechos y libertades de los ciudadanos y de una manera directa sobre su libertad, integridad y seguridad.

El policía actúa sobre estos derechos de forma directa, sin intermediarios $y$ al margen de vigias que controlen su proceder. El ciudadano bajo sospecha de estar implicado en un hecho definido como delito, en esos primeros momentos de la actuación policial, sólo está protegido por el respeto del agente a la legalidad y sus sentimientos democráticos.

La idea predominante que todavía hoy, en una situación democrática, orienta la política de los órganos responsables de la actuación policial insiste en la eficacia y no alimenta la esperanza de los que pretenden la renovación por la vía de la normalidad democrática. La reflexión, el análisis $y$ el respeto a los derechos individuales son necesarios para consolidad el sistema, y todavía está por demostrar qu su vigencia haga disminuir la eficacia con respecto a experiencias vividas anteriormente, claramente negativas.

En una línea maximalista y de pleno reconocimiento de los derechos, hay que pensar que el desarrollo democrático de la organización policial reposa en las leyes que estructuran su organización y funciones. La Policía, como órgano integrado en la Administración civil del Estado, debe reflejar los principios constitucionales que configuran la función pública, 
manteniéndose alejada de las especialidades que caracterizan la institución militar ${ }^{25}$.

Las lineas de la organización pasan por: la sumisión a la legalidad, el reconocimiento de los derechos de sindicación y huelga, garantías de imparcialidad para el ejercicio de su función y ausencia de privilegios e inmunidades, pues cualquier pretensión en este sentido resultaría antidemocrática ${ }^{26}$.

Esta línea de máxima reivindicación de derechos para el aparato policial fue la nota predominante que apareció en editoriales y artículos de prensa nacional, siendo el primer cauce de expresión a través del cual el ciudadano comenzó a tener constancia de la gravedad del problema, ante la inminente aparición de la Ley Orgánica de Fuerzas y Cuerpos de Seguridad. Asi, por ejemplo, nos encontramos opiniones como la de J.A. MARTÍN PALLíN, Fiscal y Presidente de la Asociación Pro Derechos Humanos, el cual denunciaba que el enfrentamiento entre las propuestas de los sindicatos policiales y la postura exteriorizada por el Ministerio del Interior se presentaba a la opinión pública como una colisión de intereses en la que el Gobierno sólo pretende defender la seguridad de todos los ciudadanos frente a las reivindicaciones corporativas e insolidarias de los funcionarios policiales, señalando textualmente que "aquí recobra su vigencia la frase de Kelsen "cuanto más fuerte es la voluntad de poder, tanto menor es el aprecio que de la libertad se hace" por cuanto cabe pensar que en esta contienda late el inveterado deseo de concentrar la mayor cantidad posi-

25 Los propios sindicatos policiales solicitaron que fueran reconocidos como unos funcionarios más. Vid. el escrito de Modificaciones al Proyecto de Ley Orgánica que propusieron el Sindicato Profesional de Policía (SPP) y la Unión Sindical de Policías (USP), los cuales, entre otras, emitieron la siguiente propuesta: «EI Cuerpo Nacional de Policia es un cuerpo de la Administración Civil del Estado dependiente del Ministerio del Interiorn; o la realizada por la Coordinadora de Sindicatos Policiales, los cuales solicitaban que se recogiese: (...) el Cuerpo de Policía del Estado, que es un cuerpo de funcionarios civiles, integrado en la Administración y dependiente del Ministerio del Interior (...) n; publicado en los medios de comunicación (octubre de 1985).

26 Resulta paradójico que sean los Tribunales los que estén a la vanguardia de la Administración. Así, la Sentencia del Tribunal Supremo de 18 de enero de 1982, en un supuesto de muerte de un paisano por disparos de la policía, condena a la Administración del Estado por "la inadmisible convicción administrativa de que la simple y pura huida de una persona, desatendiendo las órdenes de "alto policia", autoriza sin más a ésta para utilizar sus armas de fuego, con resultado mortal para quien huye, olvidando que la vida humana es el supremo bien de nuestra cultura y ordenamiento jurídico, según consagra el artículo 15 de nuestra Constitución, que ninguna persona o autoridad puede destruir» («todos tienen derecho a la vida y a la integridad física y moral, sin que, en ningún caso, puedan ser sometidos $[\ldots] »)$. 
ble de poder en la esfera del Ejecutivo, en detrimento de las libertades individuales" ${ }^{27}$. Esta afirmación venía a realizarla pues, en su opinión, tras observar la transferencia de los esquemas de actuación de la institución militar a las normas reguladoras de la policía que aparecía de forma indisimulada en las líneas fundamentales del proyecto, debido sobre todo a una lectura tangencial del texto constitucional.

En este mismo sentido podriamos destacar las opiniones, por ejemplo, de M. MIRAVET HOMBRADOS, fiscal de la Audiencia Territorial de Valencia, quien señalaba que "es necesario superar determinadas posiciones pseudo-izquierdistas de una concepción de la Policía aislada de la sociedad y defendiendo, por el contrario, que especialmente en una sociedad democrática es necesaria una policía inserta en la sociedad y comprendida por ésta a la que, en definitiva, sirve» ${ }^{28}$, o de M. BALLBÉ, Profesor de Derecho Administrativo de la Universidad de Barcelona, el cual señaló, en las mesas redondas para debatir la "reforma policial» organizadas en noviembre de 1985, que: "Sólo podremos vivir en una democracia consolidada si tenemos una administración policial verdaderamente civil. Una prueba de ello la encontramos en el origen que tradicionalmente han tenido los golpistas españoles, que no venian del ejército, sino que eran militares más bien vinculados a la administración policial, desde el golpe de Pavía hasta el 23-F, pasando por el 18 de julion ${ }^{29}$.

Este amplio abanico de opiniones coincidió con la ruptura de las negociaciones y conversaciones entre el Ministerio del Interior, en la figura de su ministro, José BARRIONUEVO, y las organizaciones sindicales policiales, sobre el Proyecto de Ley aprobado en septiembre por el Consejo de Ministros. Ante la remisión del Proyecto a las Cámaras para su debate, los sindicatos propugnaban la reforma de varios aspectos de este Proyecto, que, sin embargo, eran negados rotundamente por el titular de Interior: 1. Militarización encubierta y falta de control por parte de los ciudadanos, según se deriva del término "Instituto Armado de naturaleza civil". 2. Dada la radical negativa a aceptar el derecho de huelga, regular su ejercicio a través de un organismo - el Tribunal de Arbitraje- que la haría innecesaria en la práctica. 3. Rechazo en la Ley de las reivindicaciones históricas de la Policía (honorarios, servicios, jubilación, retribuciones, etc.) 4. Completa militarización de la Guardia Civil.

Esta ruptura tuvo como consecuencia el inicio de una amplia campaña contra el Proyecto de Ley, por parte del sindicato policial mayoritario.

27 Cfr. diario El País del 5 de octubre de 1985.

28 Cfr. diario Las Provincias del 13 de noviembre de 1985.

29 Cfr. diario Levante del 6 de noviembre de 1985. 
Sindicato Unificado de Policia (SUP), la cual, en su primera fase, intentaba realizar un llamamiento a la opinión pública en general y animar a los ciudadanos «a una aportación directa en prensa, radio y televisión, en defensa de una Policía eficaz, profesional y civil»» ${ }^{30}$, en un intento de que los ciudadanos comenzasen a tener conocimiento de los problemas reales que había padecido durante tanto tiempo, un colectivo tan importante como el policial. $Y$ es que este Proyecto de Ley representaba una oportunidad histórica para que los miembros del colectivo policial vieran un verdadero cambio en sus estructuras.

Vamos a intentar, a partir de ahora, fijarnos ya en la redacción definitiva del texto orgánico, haciendo una referencia y descripción de los distintos y variados problemas que aparecen, su posterior regulación en el texto definitivo y los diferentes cambios propuestos por las fuerzas políticas en los debates parlamentarios. Todo ello en un intento de dejar patente todos los puntos básicos objeto de conflicto entre el Ministerio del Interior y las fuerzas sindicales, y que dieron lugar a tensiones y medidas de fuerza en pro de conseguir un acuerdo mutuo que parecía muy distante.

\section{Los principios básicos funcionales}

Analizando en primer lugar el contenido básico y general del texto, nos encontramos con que el Pleno del Congreso de los Diputados, en su sesión del día 25 de febrero de 1986 31, aprobó el Proyecto de Ley Orgánica de Fuerzas y Cuerpos de Seguridad, después de haber sido defendidas 658 enmiendas, por parte de los diferentes grupos parlamentarios. Este dato nos puede dar una idea de lo largo y complicado que fue el debate, ya que a cada respecto del texto se acumulaban un gran número de enmiendas.

Es claro que el clima de expectación que se vivía en el seno de la opinión pública se traspasó a las Cámaras en forma de enmiendas en voz de los parlametarios. Y ya fue un logro el que se pudiera reducir el número de enmiendas para el Pleno del Congreso, dado que en el informe de la Ponencia ${ }^{32}$ fue donde más variaciones se recogieron, siendo las propuestas de modificación del texto mucho más elevadas que el número de enmiendas antes reseñado.

30 Manifiesto del SUP recogido en toda la prensa nacional. Cfr. el Diario 16 de 1 de noviembre de 1985, pág. 11.

$31 B O C$ de 3 de marzo de 1986, págs. $3170 / 157$ ss.

$32 \quad B O C$ de 25 de noviembre de 1985, Serie A, núm. 163-1-2, págs. 3170/3 a 61 . 
En todo caso, ante este debate en el Pleno, existía en todos los portavoces de la oposición el sentimiento de aceptación de la labor realizada en el Informe de la Ponencia, dado que habían sido aceptadas muchas modificaciones que mejoraban sustancialmente el texto inicial del proyecto. Cabe resaltar, por ejemplo, en representación de este sentimiento, la opinión del parlamentario de Minoría Catalana señor TRÍAS DE BES, quien puntualizó que el texto de la ley "ha mejorado mucho en su paso por la ponencia, y estoy seguro de que vamos a llegar a un acuerdo global sobre el texto de la Ley en los distintos trámites parlamentarios» ${ }^{33}$.

Esta ley tiene en su mayor parte carácter de Ley Orgánica y pretende ser omnicomprensiva, acogiendo la problemática de las Fuerzas y Cuer-. pos de Seguridad del Estado, de las Comunidades Autónomas y de las Corporaciones Locales, según destaca en su preámbulo.

Su objetivo pricipal se centra en el diseño de las líneas maestras del régimen jurídico de las Fuerzas y Cuerpos de Seguridad, en su conjunto, tanto de las dependientes del Gobierno de la Nación como de las Policías Autónomas y Locales, estableciendo los principios básicos de actuación comunes a todos ellos y fijando sus criterios estatutarios fundamentales.

Sin embargo, algunos aspectos de la Ley -especialmente los relativos al proceso de integración de los Cuerpos Superior de Policía Nacional en el nuevo Cuerpo Nacional de Policía- no tienen el carácter de Ley Orgánica, lo que impone la determinación, a través de una disposición final, de los preceptos que tienen ese carácter ${ }^{34}$.

Siguiendo las lineas marcadas por el Consejo de Europa, en su «Declaración sobre la Policía», y por la Asamblea General de las Naciones Unidas, en el "Código de conducta para los funcionarios encargados de hacer cumplir la ley", se establecen los principios básicos de actuación a modo de auténtico "Código deontológico", que vincula a los miembros de todos los colectivos policiales, imponiendo el respeto a la Consitución, el servicio permanente a la comunidad, la adecuación entre fines y medios como criterio orientativo de su actuación, el secreto profesional, el respeto al honor y dignidad de la persona, la subordinación a la autoridad y la responsabilidad en el ejercicio de la función (art. $5 .^{\circ}$ de la Ley).

A pesar de que se recojan de una forma más detallada los prin-

33 Cfr. Diario 16 del 21 de noviembre de 1985.

${ }^{34}$ Según la disposición final $5 .^{a}$, quedan excluidos los artículos 10, 11.2 a $11.6,12.1$ y 17 , asi como las disposiciones transitorias, adicionales $1 .^{a}$ y $4 .^{a}$ y derogatoria. 
cipios básicos de actuación y las disposiciones estatutarias comunes en los artículos $4 .^{\circ}$ y $5 .^{\circ}$ de la Ley, en la discusión parlamentaria del Pleno del Congreso se propusieron varias modificaciones a través de enmiendas, cuyo espíritu era el de añadir o matizar aspectos que habían quedadò fuera del articulado del Dictamen de la Comisión.

Tales enmiendas, en su conjunto, fueron más bien matices terminológicos o recordatorios de principios u obligaciones que, si bien no aparecían expresamente en el articulado, se reconcocía que aparecían implícitamente en otras partes del texto.

Así, por ejemplo, se solicitaba que dentro del punto referido a la dedicación profesional apareciera la exigencia de que todos los funcionarios que pertenecieran a los Cuerpos y Fuerzas de Seguridad del Estado ejercieran su función en régimen de dedicación exclusiva ${ }^{35}$, siendo ésta una exigencia que, sin embargo, ya aparecía en la actual legislación precedente a la Ley Orgánica, aunque es posible que se justificara su presencia, si se hubiese aprobado la enmienda, teniendo en cuenta que es un articulado que se dirige a todas las Policías, por lo que tal vez hubiera resultado más beneficioso el que se recogiese este principio, pensando que también va dirigido a las Policías de las Comunidades Autónomas y a las Policías Locales.

Se solicitó, de igual forma, una mayor especificidad de las normas generales bajo las que debe regirse la actuación policial, en busca de una mayor coherencia con las resoluciones de la Asamblea Parlamentaria del Consejo de Europa sobre Policía. Incluso se llegó a solicitar la constatación expresa, en este artículo, de los aspectos sancionatorios de las infracciones más propias de su actuación. En este sentido, pensamos que en todo caso debían recogerse estas sanciones en el precepto destinado a las sanciones disciplinarias, pues lo contrario iría en perjuicio del espíritu positivo del precepto, pues estos principios básicos de actuación tienen que formar un auténtico código de conducta policial.

Al señalarse que la Policía debe adecuarse en sus actuaciones al ordenamiento jurídico y respecto a la Constitución, y a los principios ya contemplados en otros textos de nuestro ordenamiento, se ha hecho que llegue a considerarse necesario el que se repitan en este texto, haciendo en lógica consecuencia que se señalara en la Ley la imposibilidad por parte de los miembros de la policía, que se realicen prácticas abusivas, arbitrarias o discriminatorias que entrañen violencia física o moral.

35 Enmienda núm. 71 presentada por el diputado señor. Sancho Rof (Grupo Parlamentario Centrista), Diario de Secciones del Congreso de los Diputados, de 5 de diciembre de 1985, págs. 11677-11678. 
Ante esta idea, en opinión de varios grupos parlamentarios, debia señalarse igualmente otra serie de ideas que ayudarían a que estas actuaciones policiales dentro de la legalidad vigente tuvieran un mayor contenido: tal sería el caso de las toruturas y los tratamientos inhumanos o degradantes, debiendo estar ambas circunstancias expresamente prohibidas $y$ sancionadas.

Igualmente, debía tipificarse la situación de que un policía pueda verse en las circunstancias de custodiar a una persona cuyo estado de salud precise de cuidados médicos. En este supuesto, debía especificarse la obligación del llamamiento al personal médico necesario y, en su caso, tomar las medias necesarias para proteger la vida y salud de esa persona ${ }^{36}$.

En el mismo sentido, y con la intención de completar estos principios en líneas marcadas por el Consejo de Europa, se trata de precisar que, en caso de la negativa por un funcionario a ejecutar una orden ilegal, no le sea aplicada ninguna medida legal ni disciplinaria ${ }^{37}$.

En el fondo, todas estas precisiones que hemos señalado tan sólo son matices, en muchas ocasiones muy leves y de simple redacción o terminológicos. Pero en todo caso es un aspecto importante que hay que destacar, pues, tratántose de un artículo que establece un nuevo modelo de Policía democrática y de una norma que fija pautas de comportamiento en la función policial -en defensa, desarrollo y cumplimiento de la función policial previamente marcada en el texto constitucional-, es de felicitarse el que, sobre este aspecto, sean mínimas las diferencias de opinión de los grupos parlamentarios que forman el amplio espectro político.

\section{La denominación «Instituto armado de carácter civil»}

Para referirse a la Policía, la Ley Orgánica utiliza la expresión "Instituto Armado de carácter civil» ${ }^{38}$, excepto al referirse a la Guardia Civil, que, pese a asumir funciones policiales, es caracterizada como «Instituto

36 Enmiendas núms. 599, 600 y 601 del señor. Vizcaya Retana, del PNVGrupo Vasco, Diario de Sesiones del Congreso de los Diputados, de 5 diciembre de 1985, págs. 11682-11683.

37 Enmienda núm. 547 del señor. Vicens Giralt de ERC (Grupo Mixto), en Diario de Sesiones del Congreso de los Diputados, de 5 de diciembre de 1985, págs. 11683-11684. En el mismo sentido hubo enmiendas por parte de los señores. Pérez Royo, del PCE (Grupo Mixto), y Trias de Bes y Serra, de la Minoría Catalana.

38 Artículos $9 .^{\circ}, 41.2$ y 52 de la Ley Orgánica 2/1986, de 13 de marzo. 
armado de carácter militar", que se estructura de conformidad con la "jerarquía militar" ${ }^{39}$ y se rige a efectos disciplinarios por su normativa específica - es decir, por la Ley 12/1985, de 27 de noviembre-.Constitucionalmente se habla de "Institutos sometidos a disciplina militar" ${ }^{40}$, expresión que debe entenderse como sumisión al régimen disciplinario propio de aquel ordenamiento, con exclusión, por la contraposición de los articulos $8 .^{\circ}$ y 104 de la Constitución, de Cuerpos policiales sometidos a la cadena de mando de cualquier Ejército.

La auténtica peculiaridad de la Guardia Civil, con todo, capaz de colorear el modelo como "militarizado", estriba en que la fuerza actuará sometida a sus jefes naturales, sin que la autoridad gubernativa pueda detener su intervención. Ya hemos dicho que en la Ley Orgánica hay base para establecer los procedimientos formales para que este efecto se produzca. Pero, fuera de aquéllos, la actuación ordinaria de la Guardia Civil, como cuerpo de Policía, no debe estar sometida ni a«jerarquía militar», en el sentido de que se asuma por el mando la responsabilidad, ni a otros principios de actuación que a los policiales. La ley es criticable, en este sentido, en la medida en que nada hace para acercar la Guardia Civil al modelo de gendarmería europea.

Respecto al Cuerpo Nacional de Policía es desmilitarizadora la previsión del pase a la situación de retirado del personal de las FF.AA. que permanezca en el Cuerpo. Pero es contradictorio con esta idea la disposición adicional 1.a, que prevé la adscripción de miembros de las FF.AA. al mando de unidades uniformadas del Cuerpo, sin determinar expresamente el pase a la situación de retiro.

Militarizador también es el contenido del artículo 43 de la Ley que, además de prever jefes, oficiales y mandos de las FF.AA. en los Cuerpos Autonómicos, establece la posibilidad de reintegrarse a su Arma de origen "en cualquier momento que lo soliciten". Queda claro, pues, que no se da una solución posible al tema de la Guardia Civil como Policía ordinaria, sino que, además, se prescinde del principio de separación de fuerzas, estableciendo una serie de puentes entre determinado personal de las FF.AA. y los Cuerpos policiales, que es la más clara imagen de la intervención del Ejército en una misión que constitucionalmente no le corresponde y que, bien se aprecia, beneficia a los profesionales de la milicia frente a los profesionales del órden público. Ello produce una grave dis-

39 Artículo 14 y 15 de la misma Ley Orgánica.

40 La expresión aparece en los artículos 28 y 29 de la Constitución de 1978. La Constitución republicana de 1931 hablaba, en su artículo 95, de "Institutos Armados" a efectos jurisdiccionales. 
funcionalidad, siendo un problema que merece ser analizado con más detalle.

Un punto esencial para conseguir la integración de las Fuerzas de Seguridad en la sociedad democrática es el de la desvinculación de la Policía respecto de las Fuerzas Armadas. Con ello se pretende decir que es indispensable para una sociedad democrática el disponer de una Policía desmilitarizada, $y$, al mismo tiempo, que la desmilitarización se convierte en una de las reivindicaciones clave para conseguir la democratización de la Policía.

Bastaría citar, como argumento aplastante en favor de la desmilitarización, el elevado número de países democráticos que cuentan con Policía de carácter civil. Así ocurre con Francia, Estados Unidos, Inglaterra, Dinamarca, Noruega, Canadá, Alemania Federal, etc., pero, aunque sea éste un argumento muy impotante, debemos recalcar que son los argumentos racionales los que hacen decantarse hacia una policía de carácter civil ${ }^{41}$.

Hay que precisar, no obstante, que algunos de estos países, como Francia, por ejemplo, tienen algún cuerpo militarizado. Pero la larga tradición democrática, ha dado como resultado que el carácter militar de la institución haya quedado diluído. Nuestro país no se encuentra en este supuesto, sino que cuenta con una Policía de larga tradición militar-autoritaria, como ya hemos venido señalando en páginas anteriores.

Ciertamente, no podrán solucionarse los graves problemas de nuestras Fuerzas de Seguridad, y no se podrá ir hacia la consolidación de la democracia, si no se reconsidera como punto fundamental del sistema político la desmilitarización de estos Cuerpos.

Sin entrar a fondo en el análisis histórico, hay que señalar que la estructura y el carácter militar de nuestra Policía procedan del Antiguo Régimen - del absolutismo-, aunque fue durante el liberalismo cuando se consolidó en el Estado consitucional la estructura policial de carácter militar. Ésta no representaba otra cosa más que la intervención del Ejéricto en la policía diaria de gobierno, en las opciones cotidianas sobre el orden público.

41 Vid., más ampliamente sobre el tema, AUBERT y PETIT: La Police en France. Paris, 1981. También Dirección General DE LA Policia: La policía francesa. Organización y régimen. Informe monográfico núm. 27, Madrid, Policía Española, 1982, y DiReCción GeneRAL DE LA Policia: La policía italiana. Organización y régimen. Informe monográfico núm. 25, Madrid, 1982. 
Desembarazarse de esta tradición es fundamental para dar credibilidad al régimen democrático, y no sólo para esto, sino simplemente para delimitar dos profesiones que son diferentes, es decir, que tiene unos fines, unos procedimientos, una estructura propios y a la vez opuestos. Lo que hay que conseguir es la adecuación de las estructuras a cada profesión, tanto a la de la Policía como a la de los militares, y conseguir asimismo que cada una cumpla eficazmente los objetivos de interés general que la sociedad les ha encomendado.

Los militares pertenecen a una profesión con unos valores, con unos métodos y unos fines que son completamente diferentes de los que debe tener la Policía.

La Constitución separó, en dos artículos (el art. $8 .^{\circ}$ y el 104), el tratamiento de la Policía y del Ejército, cumpliendo con ello una de las condiciones (separación de fuerzas) para diseñar un aparato de seguridad pública democrático y liberal, configurando la Policía como servicio público ${ }^{42}$.

La segunda exigencia de la tradicional dogmática del orden público democrático, la diferenciación de fines, también aparece recogida constitucionalmente: por un lado, la integridad del territoiro nacional, la soberanía del Estado y el ordenamiento constitucional, como misión de las Fuerzas Armadas ${ }^{43}, y$, por otro, la garantía de la seguridad ciudadana y el libre ejercicio de los derechos de los ciudadanos, como fin de los Cuerpos y Fuerzas de Seguridad.

Ambos datos ponen de manifiesto que la Constitución considera incongruente la utilización del Ejército o de sus procedimientos en misiones de orden público -en circunstancias de normalidad, cuando el ordenamiento constitucional no está amenazado-. En efecto, la distinta naturaleza del "enemigo" (un ciudadano o un delincuente no lo es), la distinta finalidad de la acción (no se trata de aniquilar físicamente al enemigo inexistente), la utilización de medios diferentes (no se trata tampoco de arrasar bienes, propiedades, comunicaciones, sino de restablecer la normalidad) e incluso el medio físico de actuación (una población, no un campo de batalla) son factores presentes en el enunciado constitucional de la misión de las Fuerzas de Seguridad.

42 Vid. M. Ballbé: "La Policía y la Constitución", en Policía y sociedad democrática. Compilado por J.M. Rico, Madrid, Alianza, 1983, págs. 89-98.

43 Hay que señalar que incluso estos fines están acotados a circuntancias muy concretas, pues, como señala el profesor Álvarez Conde, las Fuerzas Armadas se encargarán de la defensa política de la Constitución, "la cual desde luego no podrá ser ejercida genéricamente, sino que tiene su ámbito específico de actuación en los supuestos estados de excepción previstos en el artículo 116 (...)". Cfr. Enrique ÁlvaRez Conde: El régimen político español. Madrid, Tecnos, 1990, pág. 308. 
Esta visión no debe enturbiarse por la redacción ambigua de los artículos 28 y 29 de la Constitución, los cuales hablan de "Institutos y Cuerpos sometidos a disciplina militar», en lugar de referirse a Fuerzas y Cuerpos de Seguridad.

Es difícil justificar el sentido de la expresión «disciplina militar». Esta referencia tenía aquí un sentido tradicional, dado que era habitual en nuestro constitucionalismo establecer limitaciones al derecho de petición que afectaban a "toda clase de Fuerzas de Armadas" (arts. 20 de la Constitución de 1869 y 13 de la de 1876) o bien aludir a «Institutos Armados» (art. 21 del Fuero de los Españoles).

La expresión pasará del artículo 33 del anteproyecto al texto de una enmienda de Minoría Catalana -la número 132 de las presentadas al anteproyecto- que servirá de base al texto definitivo del artículo 28 , donde la reiteración puede ocasionar ambigüedades.

Para BALLBÉ, tal ambigüedad no puede manipularse en contra de lo prescrito en los artículos $8 .^{\circ}$ y 104 , de forma que no puede haber Fuerzas o Cuerpos de Seguridad sometidos a disciplina militar, porque sólo pueden estarlo los pertenecientes a las Fuerzas Armadas, y éstas no tienen asignadas misiones de Policía en tiempo de paz. A su entender, los Cuerpos policiales deben incluirse donde se habla de "instituciones armadas", que de ninguna forma pueden tener la misma escala de mando, ni la disciplina perteneciente exclusivamente a las Fuerzas Armadas. Es decir, no pueden ser Cuerpos militares y sólo estar sometidos a disciplina militar una vez declarado el estado de excepción ${ }^{44}$.

Por su parte, SANTAMARÍA entendió que la expresión "Fuerzas e Institutos armados" alude a las Fuerzas Armadas y a la Guardia Civil. La otra parte del texto constitucional ( ( los demás Cuerpos sometidos a disciplina militar»), por la propia imprecisión de los conceptos manejados, podría interpretarse en sentido formal (estructura y organización militares), jurídico (procedimientos disciplinarios y jurisdiccionales castrenses) o puramente material (Cuerpos de alto grado de disciplina y jerarquía interna similares a las de la milicia). El autor concluye afirmando que la expresión "disciplina militar" hace referencia aproximadamente a los Cuerpos $y$ Fuerzas de Policía (Cuerpo Superior, Policía Nacional, Policías Autónomas y Locales) en cuanto ejercen la coacción física mediante encuadramiento del personal según rígidas técnicas parecidas a las militares ${ }^{45}$.

44 Vid. M. BALlBÉ: Orden público y militarismo en el constitucionalismo español. Barcelona, Ariel, 1981, pág. 462.

45 Cfr. J. Santamaría: "Comentario al artículo 28 de la Constitución", en Comentarios a la Constitución, dirigidos por Garrido Falla, 2. ed., Madrid, Cívitas, 1983 , págs. $569-575$. 
Si se entiende el tenor literal de los artículos 28 y 29 de la Constitución en sentido técnico, es difícil integrar el contenido de los artículos $8 .^{\circ}$ y 104 de la propia Constitución. Es ésta, como sabemos, las Fuerzas Armadas y Cuerpos de Seguridad no forman parte de las Fuerzas Armadas, de forma que tampoco aquellos "Institutos" y "Cuerpos" sometidos a disciplina militar, si desempeñan funciones policiales, se integran en aquéllas.

En nuestra opinión, parece que la Constitución no ha utilizado en el artículo 28 la expresión "disciplina militar" en sentido totalmente técnico o aproximativo, pero tampoco en su puro sentido totalmente jurídico. De los datos seguros que el análisis constitucional suministra (no integración en tiempo de paz de las Fuerzas y Cuerpos de Seguridad en las Fuerzas Armadas, diferenciación funcional Ejército-Policía) se sigue que la "disciplina militar" en el sentido de los artículos 28 y 29 de la Constitución excluye de su ámbito técnico la normativa reguladora de las relaciones entre militares (mando militar) y del peculiar principio de subordinacion jerárquica (jerarquía de grado). Ello supone que no existe la posibilidad constitucional de Cuerpo o Fuerzas de Seguridad sujetos a la escala de mando de cualquier Ejército.

Por el contrario, la referencia de los artículos 28 y 29 de la Constitución supondría la posibilidad de aplicar, al menos parcialmente, el status militar a los miembros de aquéllos, así como las medidas sancionadoras consiguientes.

Pero es necesario volver a repetir una idea básica: la Policía es, y así debe reconocerse en nuestro país, un servicio público, teniendo como tarea principal la protección y garantía de los derechos fundametales reconocidos en nuestra Constitución. Si actúa o interviene es para defender los derechos de los ciudadanos; sólo para ello puede tener fundamento su intervención coerecitiva, pero asi $y$ todo esta intervención debe estar de acuerdo con los valores fundamentales $y$ basarse en principios democráticos. Sin embargo, todas estas afirmaciones, aunque estuviesen contenidas en la Ley, no serían suficientes. Es necesario adecuar el aparato de Policía a estas finalidades, radicalmente opuestas a las que ha tenido hasta ahora.

Y ésta es la intención que, en principio, expresa la ley Orgánica: por encima de cualquier otra finalidad, pretende ser el inicio de una nueva etapa en la que destaque la consideración de la Policía como un servicio público dirigido a la protección de la comunidad, mediante la defensa del ordenamiento democrático.

Así pues, conviene destacar el principio de obediencia debida, reco- 
gido con un significado especial, al disponerse que la misma, en ningún caso, podrá amparar actos manifiestamente ilegales ordenados por los superiores (recordamos aquí que se había intentado mejorar el texto durante los debates parlamentarios, proponiéndose la inclusión explícita de la no sanción a los funcionarios que se negasen a cumplir órdenes manifiestamente ilegales). También es digna de mención la obligación que se impone, a los miembros de las Fuerzas y Cuerpos de Seguridad, de evitar cualquier práctica abusiva, arbitraria o discriminatoria que entrañe violencia física o moral.

En el aspecto estatutario, la Ley pretende configurar una organización policial, basada en criterios de profesionalidad y eficacia, atribuyendo una especial importancia a la formación permanente de los funcionarios y a la promoción profesional de los mismos. Con carácter general, se regula la práctica totalidad de los aspectos especiales y esenciales, integrantes de su estatuto personal (promoción profesional, régimen de trabajo, sindicación, incompatiblidad, responsabilidad, etc.).

\section{A MODO DE CONCLUSIÓN}

Al respecto de estas ideas marcadas en la Ley, es claro que el respeto a los derechos fundamentales significa, entre otras cosas, una mentalidad y un comportamiento diferentes. Es evidente que la organización de la Policía debe estar modelada sobre estas bases, y que su forma de actuar debe ser la que corresponde a una Policía democrática. En lógica consecuencia, no puede intervenir con violencia desproporcionada, "legitimada" por el hecho de estar respaldada por el mismo Estado.

Esta idea es clara. Sin embargo, y fundándose en estos mismos argumentos, la Ley utiliza este fin para justificar la interdicción de la huelga o de las acciones sutitutivas de la misma. Para argumentar esta acción, se remite al marco delimitado por el artículo 28 de la Constitución, ya analizado anteriormente, y establece la interdicción en áreas de los intereses preeminentes que corresponde proteger a los Cuerpos de Seguridad, con la única justificación de asegurar la prestación continuada de sus servicios, los cuales no admiten interrupción.

Pensamos que, tal vez, hubiese sido mejor un reconocimiento del derecho de huelga a los policías, y posteriormente realizar una serie de limitaciones, pues incluso los mismos policías son conscientes de su necesidad, dado que ellos son los primeros en reconocer la especial importan- 
cia de su función en la sociedad. Sin embargo, no se realiza así, y lo que se produce es un nuevo giro hacia posiciones anteriores. Es patente la importancia del fin atribuido a la Policía, pero un recorte tan brusco provoca de nuevo la similitud al sistema militar, lo que hace permanecer en cierta medida los valores castrenses.

Ciertamente, si permanecen los valores castrenses en la profesión policial, seguiremos bajo el mismo esquema y con los mismos problemas, incumpliendo las Fuerzas de Seguridad las finalidades que la sociedad les ha encomendado: el mantenimiento de la pacífica convivencia civil dentro del ejercicio de las libertades.

En conclusión, se produce una ruptura patente del tenor literal del artículo 104 en relación al desarrollo ambiguo de la Ley Orgánica, lo cual produce el que se entre en la consideración de una mdificación o reforma de los aspectos estructurales de la citada ley de desarrollo, o que, en su caso, dejemos una clara constatación de un nuevo incumplimiento constitucional al no respetarse el sentido concluyente de la norma fundamental ${ }^{46}$.

46 Véase para mejor conocimiento, "Policía y Sociedad", I Seminario U.I.M.P. y Dirección General de la Policía, Ministerio del Interior, Santander, 1989. 